\title{
$\mathrm{N}$-acetylcysteine resists high-glucose-induced injury of human umbilical vein endothelial cells by inhibiting the leptin/leptin receptor
}

\section{Zhenhua Wang}

People's Hospital of Baoan District

Jun Chen

People's Hospital of Baoan District

Shuping Lian

People's Hospital of Heyuan

Kaibin Liao

People's Hospital of Shiyan

\section{Lizhi Huang}

People's Hospital of Baoan District

Chaosheng Li ( $\sim 510505698 @ q q . c o m$ )

\section{Research article}

Keywords: $\mathrm{N}$ - acetylcysteine, Leptin, Leptin receptor, High glucose, Human umbilical vein endothelial cells

Posted Date: March 23rd, 2020

DOI: https://doi.org/10.21203/rs.3.rs-18647/v1

License: (c) (1) This work is licensed under a Creative Commons Attribution 4.0 International License. Read Full License 


\section{Abstract}

Baclground The present study aimed to investigate whether $\mathrm{N}$ - acetylcysteine (NAC) protects human umbilical vein endothelial cells (HUVECs) against high glucose (HG)-induced injury by inhibiting leptin/leptin receptor (LEPR).

Methods HUVECs were treated with $40 \mathrm{mmol} / \mathrm{L}$ glucose for $24 \mathrm{~h}$ to establish a model of HG-induced endothelial cell injury; The cell viability was examined by cell counter kit-8(CCK-8) assay; The expression levels of leptin, LEPR, cleaved caspase- 3 and endothelial nitric oxide synthase (eNOS) were detected by western blot. The intracellular levels of reactive oxygen species (ROS) were tested by DCFH-DA staining followed by photofluorography. Tumor necrosis factor-a (TNF-a) घnuclear factor-kappa B (NF-kB) and intercellular adhesion molecule-1 (ICAM-1) were detected by enzyme-linked immunosorbent assay (ELISA). The number of apoptotic cells was observed by photofluorograph with Hoechst 33258 nuclear staining. Mitochondrial membrane potential (MMP) was obtained using JC-1.

Results The expression of leptin and LEPR began to significantly increase after exposure to $40 \mathrm{mmol} / \mathrm{L}$ HG for $24 \mathrm{~h}$. Pretreatment of HUVECs with $7 \mathrm{mmol} / \mathrm{L}$ NAC or $50 \mathrm{ng} / \mathrm{mL}$ leptin antagonists (LA) for 30min inhibited the increased expression of leptin and LEPR induced by HG in HUVECs. Furthermore, pretreatment with $7 \mathrm{mmol} / \mathrm{L} \mathrm{NAC}$ or $50 \mathrm{ng} / \mathrm{mL}$ LA for $30 \mathrm{~min}$ also inhibited HG-induced injury, by increasing the cell viability and eNOS expression, and decreasing the inflammatory response and cleaved caspase-3 expression, the apoptotic cells and generation of intracellular ROS and a loss of MMP.

Conclusions NAC protects the HUVECs against HG-induced injury by inhibiting leptin/LEPR.

\section{Background}

The number of patients with diabetes continues to increase with the aging of the global population. In 2015 , the total number of adults with diabetes worldwide was 415 million, which is predicted to increase to 642 million by $2040{ }^{[1]}$. Diabetic angiopathy is the most common chronic complication in patients with diabetes and also the main cause of blindness, amputation, and death, thus seriously affecting the prognosis and quality of life of patients. Vascular endothelial dysfunction is the initiating factor for diabetic angiopathy ${ }^{[2]}$. Therefore, protecting endothelial cells from injury in a high glucose (HG) environment is very important for the prevention and treatment of diabetic angiopathy ${ }^{[3]}$. Leptin is a 16$\mathrm{kDa}$ peptide secreted by adipocytes and other cells, which is involved in regulating appetite and energy metabolism. Leptin/leptin receptor (LEPR) damages vascular endothelial cells, affects the normal vasomotor function, and participates in the occurrence and development of diabetic vascular complications ${ }^{[4,5]}$. Wu et al. ${ }^{[6]}$ showed that hydrogen sulfide, an antioxidant, could inhibit the accumulation of reactive oxygen species (ROS) and the loss of mitochondrial membrane potential (MMP) by inhibiting leptin/LEPR, so as to prevent the injury to human umbilical vein endothelial cells (HUVECs) induced by HG. As an antioxidant, N-acetylcysteine (NAC) can reduce oxidative stress and resist $\mathrm{HG}$-induced vascular endothelial cell injury ${ }^{[7,8]}$. Studies confirmed that NAC could prevent leptin- 
induced angiogenesis ${ }^{[9]}$. However, the role and mechanism of leptin/LEPR in the effect of NAC against HG-induced endothelial cell loss have not been clarified. Therefore, the present study established an HGinduced HUVECs injury model so as to investigate the effect of HG on the protein expression of leptin/LEPR in HUVECs, and whether NAC protected HUVECs against HG-induced injury by inhibiting the leptin/LEPR.

\section{Methods}

\section{Materials}

Leptin and LEPR antibodies were purchased from Protein Tech (IL, USA). Leptin antagonists (LA) were purchased from Beijing XMJ Scientific Co., Ltd. (Beijing, China). NAC, 2',7'-dichloro-fluorescein diacetate (DCFH-DA) and Hoechst 33258 were purchased from Sigma-Aldrich (St Louis, Mo, USA). The Cell Counting Kit-8 (CCK-8) was purchased from Dojindo Molecular Technologies, Inc. (Kumamoto, Japan). Nuclear factor-kappa B (NF-kB), tumor necrosis factor-a (TNF-a), intercellular adhesion molecule-1 (ICAM1), and enzyme-linked immunosorbent assay (ELISA) kit were purchased from Cloud-Clone COPR. (CCC) (Wuhan, China). A bicinchoninic acid (BCA) protein assay kit was purchased from Beyotime Biotechnology Co., Ltd. (Shanghai, China). A 5',6,6'-tetrachloro-1,1',3,3'-tetraethyl-imidacarbocyanine iodide (JC-1) kit was purchased from Beijing Solarbio Technology Co., Ltd. (Beijing, China). Roswell Park Memorial Institute (RPMI)-1640 medium and fetal bovine serum (FBS) were purchased from Hyclone (Logan, UT).

\section{Cell culture and grouping}

HUVECs were purchased from Cell Culture Center, Institute of Biochemistry and Cell Biology (Shanghai, China). The cells were cultured in RPMI- 1640 medium with $10 \% \mathrm{FBS}$ at $37^{\circ} \mathrm{C}$ in $5 \% \mathrm{CO}_{2}$ atmosphere. After the cells were fused, trypsin was added for digestion. An equal volume of the culture medium was added to terminate the trypsin digestion when the cell mass began to disperse and some cells fell off. Sterilized pipette tips were used to blow off the cells on the bottle wall to form a cell suspension. After centrifugation at $1000 \mathrm{rpm}$ for $5 \mathrm{~min}$, the supernatant was discarded and passaged at a ratio of 1:5.

The cells were cultured with $40 \mathrm{mmol} / \mathrm{L}$ glucose for $24 \mathrm{~h}$ to establish a model of HG-induced HUVEC injury. The experiment was designed to have six groups. Control (CTL) group: HUVECs were treated with $5.5 \mathrm{mmol} / \mathrm{L}$ glucose for $24 \mathrm{~h}$; HG group: HUVECs were treated with $40 \mathrm{mmol} / \mathrm{L}$ glucose (HG) for $24 \mathrm{~h}$; HG + NAC group: HUVECs were pretreated with $7 \mathrm{mmol} / \mathrm{L}$ NAC for $30 \mathrm{~min}$ prior to exposure to HG for $24 \mathrm{~h}$; HG + LA group: HUVECs were pretreated with $50 \mathrm{ng} / \mathrm{mL}$ LA for 30 min prior to exposure to HG for $24 \mathrm{~h}$. NAC group: HUVECs were pretreated with NAC for 30 min; LA group: HUVECs were pretreated with $50 \mathrm{ng} / \mathrm{mL}$ LA for $30 \mathrm{~min}$.

\section{Measurement of cell viability}


HUVECs were inoculated in 96-well culture plates and cultured at $37^{\circ} \mathrm{C}$ in $5 \% \mathrm{CO}_{2}$ atmosphere. After the cell adhered to the wall and spread over the bottom of the well, different treatments were given according to the experimental requirements. Then, $10 \mu \mathrm{L} \mathrm{CCK-8} \mathrm{solution} \mathrm{was} \mathrm{added} \mathrm{to} \mathrm{each} \mathrm{well,} \mathrm{and} \mathrm{the} \mathrm{plate} \mathrm{was}$ incubated at $37{ }^{\circ} \mathrm{C}$ for $3-4 \mathrm{~h}$. Further, $10 \mu \mathrm{L}$ termination solution was added to each well, and immediately mixed. The absorbance $(A)$ of each well was detected by a microplate reader with the wavelength of $450 \mathrm{~nm}$. The cell viability was calculated according to the formula: cell viability $(\%)=(A$ value of treatment group - A value of Blank) / (A value of control group - A value of Blank) $\times 100 \%$. The experiments were repeated 5 times.

\section{Western blot}

HUVECs were inoculated on a $60-\mathrm{nm}$ culture dish. When cells grew to the area of $80 \%$ of the wall, they were given different treatments according to the experimental requirements. The culture medium was removed, and the cells were washed twice with precooled PBS. RIPA lysis buffer was added, and the cells were lysed at $4^{\circ} \mathrm{C}$ for $30 \mathrm{~min}$. The lysate was centrifuged at 12,000 rpm for $10 \mathrm{~min}$, and the supernatant was obtained. The protein concentration was determined using a BCA protein assay kit. The total protein was separated by SDS-PAGE and transferred to PVDF membranes. Then, $5 \%$ skimmed milk was used for blocking on the shaking table at room temperature for $1 \mathrm{~h}$, and corresponding primary antibodies were added and incubated at $4^{\circ} \mathrm{C}$ overnight. The membranes were washed with TBS-T three times (10 min each time), and secondary antibodies (1:5000) were added and incubated for $1 \mathrm{~h}$ at room temperature on the shaking table. The membranes were washed with TBS-T three times (10 min each time), and ECL liquid was used to color the PVDF membranes. The films were exposed in the darkroom, and the results were analyzed using the gel scanning system. The experiments were repeated five times.

\section{Examination of intracellular ROS}

ROS were detected using fluorescent probe DCFH-DA in the ROS detection kit. DCFH-DA without fluorescence could penetrate the cell membrane freely and was hydrolyzed by intracellular esterase into DCFH. DCFH could not penetrate the cell membrane freely and was oxidized by intracellular ROS into DCF with fluorescence. The fluorescence intensity of DCF could reflect the intracellular ROS level. HUVECs were inoculated in a 6-well culture plate and treated with different factors according to experimental requirements after the cells attached to the wall. The cells were washed with phosphate-buffered saline (PBS) three times. Subsequently, the cells were incubated with $10 \mu \mathrm{mol} / \mathrm{L} \mathrm{DCFH-DA}$ at $37^{\circ} \mathrm{C}$ for $20 \mathrm{~min}$. The cells were then washed with PBS three times, and anti-fluorescence quenching HistoChoice mounting media was used for sealing. Under the fluorescence microscope, 5 unrepeated area were randomly selected and photographed, and the average green fluorescence intensity of each field was analyzed by ImageJ 1.41 software. The experiments were repeated five times.

\section{ELISA for detecting the expression of NF-KB, TNF-a, and ICAM-1}

HUVECs were seeded in 96-well plate and treated differently according the experimental requirements. The culture supernatant of each group of cells was taken and centrifuged. The supernatant was taken 
and diluted twice with PBS for preparing the sample to be tested. The serum samples or standards of different concentrations ( $100 \mu \mathrm{L} /$ well) were added to the corresponding wells and incubated at $37^{\circ} \mathrm{C}$ for $60 \mathrm{~min}$. The liquid was discarded and dried without washing. Next, $100 \mu \mathrm{L}$ of working solution A was added to each well and incubated at $37^{\circ} \mathrm{C}$ for $60 \mathrm{~min}$. The liquid in the well was discarded, and the well was washed three times with 1-2 min of standing each time. The plate was put on a thick absorbent paper finally and patted dry gently. Further, $100 \mu \mathrm{L}$ of working solution B was added to each well and incubated at $37^{\circ} \mathrm{C}$ for $30 \mathrm{~min}$. The liquid in the well was discarded, and the well was washed five times with 1-2 min of standing each time. The plate was put on a thick absorbent paper finally and patted dry gently. The TMB substrate solution ( $90 \mu \mathrm{L} /$ well) was added to develop color at $37^{\circ} \mathrm{C}$ for $10-20 \mathrm{~min}$, avoiding light. The termination solution $(50 \mu \mathrm{L} /$ well) was added and mixed. The OD450 value was measured immediately after mixing. The experiments were repeated five times.

\section{Hoechst 33258 nuclear staining for analyzing apoptosis}

HUVECs were inoculated on a 6-well plate and treated differently according to the experimental requirements. The plate was rinsed with PBS three times ( 3 min each time). The fixation solution was added for $10 \mathrm{~min}$, and the plate was rinsed with PBS three times ( 3 min each time). The Hoechst 33258 staining solution was added for $10 \mathrm{~min}$, and the plate was rinsed with PBS four times ( 5 min each time). Finally, five unrepeated areas were randomly selected and photographed under the fluorescence microscope, and the average green fluorescence intensity of each field was analyzed using ImageJ 1.41 software. The experiments were repeated five times.

\section{Determination of MMP}

JC-1 is both a monomer and a polymer. At low concentration, JC-1 is in the form of a monomer, showing green fluorescence; at high concentration, it is in the form of a polymer, showing red fluorescence. Its absorption value changes with the change in cellular MMP. Therefore, MMP could be determined qualitatively and quantitatively by detecting green and red fluorescence. HUVECs were inoculated on a six-well culture plates and cultured at $37^{\circ} \mathrm{C}$ in the presence of $5 \% \mathrm{CO}_{2}$. Following the designated treatments, the plate was washed with PBS three times. Then, $10 \mu \mathrm{g} / \mathrm{mL} \mathrm{JC}-1$ was added and coincubated with HUVECs in an incubator at $37^{\circ} \mathrm{C}$ for $30 \mathrm{~min}$. The plate was washed with PBS three times and sealed with anti-fluorescence quenching HistoChoice mounting media. Five unrepeated areas were randomly selected and photographed under the fluorescence microscope, and the average green fluorescence intensity of each field was analyzed using ImageJ 1.41 software. The samples of each group were statistically analyzed. The experiments were repeated five times.

\section{Statistical analysis}

Statistical analysis was performed using SPSS 20.0 and GraphPad Prism 6.0 software. All data are presented as the mean \pm standard deviation (SD). Differences between groups were analyzed using oneway analysis of variance. $\mathrm{P} \bigotimes 0.05$ was considered to indicate a statistically significant difference.

\section{Results}




\section{NAC inhibits HG-induced cytotoxicity in HUVECs}

When HUVECs were treated with $40 \mathrm{mmol} / \mathrm{L}$ glucose for $24 \mathrm{~h}$, the cytotoxicity of HUVECs significantly increased and the cell viability decreased to $(26.1 \pm 1.9) \%$. Before HG treatment, HUVECs were pretreated with $1,3,5,7$, and $9 \mathrm{mmol} / \mathrm{L} \mathrm{NAC}$ for $30 \mathrm{~min}$. The cell viability increased gradually with the increase in NAC concentration. Among them, HUVECs which were pretreated with $7 \mathrm{mmol} / \mathrm{L} \mathrm{NAC}$ had the peak cell viability rate, which was significantly different from that in the HG group and $9 \mathrm{mmol} / \mathrm{L}$ NAC group $(P<$ 0.05). The pretreatment of cells with $9 \mathrm{mmol} / \mathrm{L} \mathrm{NAC}$ alone for $30 \mathrm{~min}$ had no significant effect on cell viability (Fig. 1A). Before HG treatment, HUVECs were pretreated with $7 \mathrm{mmol} / \mathrm{L} \mathrm{NAC}$ and $50 \mathrm{ng} / \mathrm{mL} \mathrm{LA}$ for 30 min. It could improve the cell viability, which was significantly different from that in the HG group $(P<0.05)$. Meanwhile, $7 \mathrm{mmol} / \mathrm{L}$ or $50 \mathrm{ng} / \mathrm{mL}$ LA had no significant effect on cell viability (Fig. 1B). Therefore, $7 \mathrm{mmol} / \mathrm{L}$ was used as the effective protective concentration of NAC in this study.

\section{NAC downregulate the increased expression of leptin and LEPR induced by HG in HUVECs}

After HUVECs were treated with $40 \mathrm{mmol} / \mathrm{L}$ glucose for $24 \mathrm{~h}$, the expression of leptin and LEPR in HUVECs significantly increased, and the difference was statistically significant compared with the CTL group $(P<0.05)$. Before HG treatment, the pretreatment with $7 \mathrm{mmol} / \mathrm{L} \mathrm{NAC}$ for 30 min could significantly decrease the expression levels of leptin and LEPR in HUVECs, and the difference was statistically significant compared with the HG group $(P<0.05)$. NAC could inhibit the expression of leptin and LEPR, but no significant difference was found compared with the HG + LA group. Treatment with $7 \mathrm{mmol} / \mathrm{L}$ NAC alone had no significant effect on the basic expression levels of leptin and LEPR in HUVECs compared with the CTL group (Fig. 2A, B).

\section{NAC reduces the oxidative stress induced by HG in HUVECs}

Treatment with HG for $24 \mathrm{~h}$ could significantly increase the generation of ROS in HUVECs, and the difference was statistically significant compared with the CTL group $(P<0.05)$. However, pretreatment with $7 \mathrm{mmol} / \mathrm{L}$ NAC or $50 \mathrm{ng} / \mathrm{mL}$ LA for 30 min could significantly reduce the accumulation of intracellular ROS, and the difference was statistically significant compared with the HG group $(P<0.05)$. Treatment with $7 \mathrm{mmol} / \mathrm{L}$ NAC or $50 \mathrm{ng} / \mathrm{mL}$ LA alone had no significant effect on intracellular ROS production (Fig. 3A, B).

\section{NAC attenuates HG-induced downregulation of eNOS in HUVECs}

Treatment with HG for $24 \mathrm{~h}$ could significantly decrease the expression levels of eNOS in HUVECs, and the difference was statistically significant compared with the CTL group $(P<0.05)$. Before HG treatment, the pretreatment with $7 \mathrm{mmol} / \mathrm{L} \mathrm{NAC}$ for 30 min could significantly attenuate the HG-induced 
downregulation of eNOS, and the difference was statistically significant $(P<0.05)$. NAC or LA had no significant effect on the expression of eNOS in HUVECs (Fig. 4).

\section{NAC suppress HG-induced inflammation in HUVECs}

Treatment with $40 \mathrm{mmol} / \mathrm{L}$ glucose for $24 \mathrm{~h}$ could increase the levels of intracellular NF-KB, ICAM-1 and TNF-a in HUVECs, and the difference was statistically significant compared with the CTL group $(P<0.05)$. Before HG treatment, pretreatment with $7 \mathrm{mmol} / \mathrm{L}$ NAC or $50 \mathrm{ng} / \mathrm{mL}$ LA for 30 min could significantly decrease the levels of NF-KB, ICAM-1 and TNF-a in HUVECs, and the difference was statistically significant compared with the HG group $(P<0.05)$. However, treatment with $7 \mathrm{mmol} / \mathrm{L}$ NAC or $50 \mathrm{ng} / \mathrm{mL}$ LA alone had no significant effect on the levels of NF-KB, ICAM-1 and TNF-a in HUVECs (Fig. 5).

\section{NAC suppress HG-induced apoptosis in HUVECs}

The results of Hoechst 33258 nuclear staining showed that the chromatin of normal vascular endothelial cells was evenly distributed and had low-density fluorescence with uniform dispersion. HUVECs which were treated with $40 \mathrm{mmol} / \mathrm{L}$ glucose for $24 \mathrm{~h}$ showed typical characteristics of apoptosis (the nuclei showed concentrated and condensed karyopyknosis or granular fluorescence), and the apoptosis rate was significantly higher than that in the CTL group $(P<0.05)$. Before $H G$ treatment, pretreatment with $7 \mathrm{mmol} / \mathrm{L}$ NAC or $50 \mathrm{ng} / \mathrm{mL}$ LA for $30 \mathrm{~min}$ could significantly inhibit HG-induced apoptosis, and the difference was statistically significant compared with the HG group $(P<0.05)$. However, NAC and LA showed no significant difference in inhibiting HG-induced apoptosis. Treatment with $7 \mathrm{mmol} / \mathrm{L} \mathrm{NAC}$ or $50 \mathrm{ng} / \mathrm{mL}$ LA alone had no significant effect on apoptosis (Fig. 6).

\section{NAC downregulates the increased expression of caspase-3 induced by HG in HUVECs}

HG could increase the expression levels of cleaved caspase-3 in HUVECs, and the difference was statistically significant compared with the CTL group $(P<0.05)$. Before $H G$ treatment, pretreatment with $7 \mathrm{mmol} / \mathrm{L}$ NAC or $50 \mathrm{ng} / \mathrm{mL}$ LA for 30 min significantly decreased the expression levels of cleaved caspase-3, and the difference was statistically significant compared with the HG group $(P<0.05)$. Treatment with $7 \mathrm{mmol} / \mathrm{L} N A C$ or $50 \mathrm{ng} / \mathrm{mL}$ LA alone had no significant effect on the protein expression levels of cleaved caspase-3 in HUVECs (Fig. 7).

\section{NAC inhibits HG-induced mitochondrial injury in HUVECs}

MMP in HUVECs was detected using JC-1. Treatment with $40 \mathrm{mmol} / \mathrm{L}$ glucose for $24 \mathrm{~h}$ could significantly increase the ratio of green fluorescence intensity to red fluorescence intensity in HUVECs, suggesting a decrease in MMP, and the difference was statistically significant compared with the CTL group $(P<0.05)$. Before HG treatment, pretreatment with $7 \mathrm{mmol} / \mathrm{L}$ NAC or $50 \mathrm{ng} / \mathrm{mL}$ LA for 30 min could significantly alleviate HG-induced decrease in MMP. Also, the ratio of green fluorescence intensity to red fluorescence 
intensity decreased, which was statistically significant compared with the HG group $(P<0.05)$. Treatment with $7 \mathrm{mmol} / \mathrm{L}$ NAC or $50 \mathrm{ng} / \mathrm{mL}$ LA alone had no significant effect on MMP in HUVECs (Fig. 8A, B).

\section{Discussion}

Hyperglycemia is an important factor for the injury to vascular endothelial cells. Its mechanism is multifaceted, including oxidative stress ${ }^{[10]}$, inflammatory response ${ }^{[11]}$, apoptosis ${ }^{[12]}$, mitochondrial injury [13], and so forth, eventually leading to the occurrence of various diabetic vascular complications. In this study, $40 \mathrm{mmol} / \mathrm{L}$ glucose was used to treat HUVECs for $24 \mathrm{~h}$ so as to establish the HG-induced endothelial cell injury model. The findings confirmed that HG had an obvious damaging effect on HUVECs, manifested in oxidative stress, increased inflammatory response of endothelial cells, apoptosis, and mitochondrial loss.

Leptin is a protein product encoded by the obesity gene, synthesized and secreted mainly by adipocytes [14]. Previous studies indicated that leptin played an important role in regulating body intake and energy metabolism. Leptin also had other functions, such as causing oxidative stress ${ }^{[15]}$, promoting inflammatory response ${ }^{[16]}$, and inducing vascular endothelial cell apoptosis ${ }^{[17]}$, which were closely related to the occurrence, development, and clinical prognosis of cardiovascular disease and diabetes [18, ${ }^{19]}$. Ryan et al. ${ }^{[20]}$ found that leptin could lead to vascular dysfunction by directly acting on LEPR. In addition, some studies also confirmed that the serum leptin level increased in patients with diabetes, indicating its involvement in the occurrence and development of diabetic vascular complications ${ }^{[21]}$. Wu et al. ${ }^{[6]}$ showed that hydrogen sulfide could inhibit the HG-induced injury in HUVECs through inhibiting leptin/LEPR. Therefore, leptin/LEPR was proven to be closely related to vascular disease and endothelial cell function.

This found that HG-induced HUVECs injury could significantly upregulate the protein expression of leptin and LEPR in endothelial cells. LA was selected to further investigate the effect of leptin/LEPR activation on HG-induced injury in HUVECs. LA is a synthetic, single-chain protein polypeptide that can block LEPR and the biological effect of leptin. This study found that LA could inhibit the protein expression of leptin/LEPR to antagonize HG-induced injury in endothelial cells, mainly manifested in improving cell viability, inhibiting oxidative stress, suppressing the inflammatory response, and reducing cell apoptosis and MMP loss, further confirming that leptin/LEPR mediated HG-induced injury in endothelial cells. Hence, inhibiting leptin/LEPR might be a new strategy for treating diabetic vascular complications.

NAC is a compound containing a sulfhydryl group. It was originally used as a mucolytic agent in treating respiratory diseases. NAC is also an ROS scavenger, which not only serves as an antioxidant and maintains the redox balance in cells ${ }^{[22]}$, but also inhibits apoptosis ${ }^{[23]}$, reduces inflammation response ${ }^{[24]}$, and is widely used for treating cardiovascular system diseases. Recchioni et al. ${ }^{[8]}$ showed that NAC

could inhibit HG-induced apoptosis in human large aortic endothelial cells. Abdelzaher et al. ${ }^{[25]}$ showed that NAC could reduce oxidative stress and blood-glucose-fluctuation-induced injury in vascular 
endothelial cells. Thus, NAC has a clear protective effect on vascular endothelial cells. However, the specific mechanism underlying NAC involvement in the HG-induced injury in vascular endothelial cells is still not clear. Previous studies found that NAC could reduce the expression level of leptin to some extent ${ }^{[26]}$ and inhibit angiogenesis by inhibiting the expression of leptin ${ }^{[9]}$. Therefore, it was speculated that NAC might be able to antagonize HG-induced multiple injuries in vascular endothelial cells through inhibiting the expression of leptin/LEPR, which was also confirmed in this study. NAC could inhibit the upregulation of leptin and LEPR induced by HG in HUVECs, implying that it could inhibit leptin/LEPR. NAC played a protective role in HG-induced injury in HUVECs, in־cluding increasing cell viability, decreasing apoptosis, inhibiting inflammatory response, and reducing ROS production and MMP loss. The mechanism might be related to the inhibition of the leptin/LEPR.

\section{Conclusion}

In summary, this study confirmed that HG could cause injury to vascular endothelial cells by activating leptin/LEPR, and NAC could prevent HG-induced injury in vascular endothelial cells by inhibiting leptin/LEPR. The findings provided new experimental evidence for further understanding the mechanism of HG-induced injury in vascular endothelial cells and the protective mechanism of NAC on vascular endothelial cells, besides new ideas for preventing and treating diabetic angiopathy.

\section{Abbreviations}

NAC

$\mathrm{N}$ - acetylcysteine

HUVECS

human umbilical vein endothelial cells

LEPR

leptin receptor

LA

Leptin antagonists

MMP

mitochondrial membrane potential

ROS

reactive oxygen species

eNOS

endothelial nitric oxide synthase

NF-KB

Nuclear factor-kappa B

TNF-a

tumor necrosis factor-a

ICAM-1 
intercellular adhesion molecule-1

\section{Declarations}

\section{Acknowledgements}

The authors thank the Shenzhen Yingfu Biological Technology Co., Ltd. for their technical help.

\section{Funding}

This work was funded and supported by Social Welfare Project of Baoan District (No.2016015).

\section{Availability of data and materials}

The datasets used and/or analyzed during the current study are available from the corresponding author on reasonable request.

\section{Authors' contributions}

ZW, CL and JC designed the study; ZW, SL and KL performed experiments; ZW, CL, SL and LH analyzed, interpreted data and drafted the manuscript; All authors read and approved the final manuscript.

\section{Ethics approval and consent to participate}

Not applicable.

\section{Consent of publication}

Not applicable.

\section{Competing interests}

The authors declare that they have no competing interests.

\section{References}

[1] Ogurtsova K, da Rocha Fernandes JD, Huang Y, Linnenkamp U, Guariguata L, Cho NH, et al. IDF Diabetes Atlas: Global estimates for the prevalence of diabetes for 2015 and 2040. Diabetes research and clinical practice. 2017;128:40-50.

[2] Madonna R, Pieragostino D, Balistreri CR, Rossi C, Geng YJ, Del Boccio P, et al. Diabetic macroangiopathy: Pathogenetic insights and novel therapeutic approaches with focus on high glucosemediated vascular damage. Vascular pharmacology. 2018. 
[3] Kobayashi T. [Possible involvement of insulin and oxidative stress in vascular dysfunction of diabetic mellitus]. Yakugaku zasshi : Journal of the Pharmaceutical Society of Japan. 2008;128:1013-21.

[4] Afarid M, Attarzadeh A, Farvardin M, Ashraf H. The Association of Serum Leptin Level and Anthropometric Measures With the Severity of Diabetic Retinopathy in Type 2 Diabetes Mellitus. Medical hypothesis, discovery \& innovation ophthalmology journal. 2018;7:156-62.

[5] Berger S, Polotsky VY. Leptin and Leptin Resistance in the Pathogenesis of Obstructive Sleep Apnea: A Possible Link to Oxidative Stress and Cardiovascular Complications. Oxidative medicine and cellular longevity. 2018;2018:5137947.

[6] Wu DB, Chen JF, Xu Q, Lin JQ, Liao JQ, Wu W. [Exogenous hydrogen sulfide inhibits high-glucoseinduced injuries via regulating leptin/leptin receptor signaling pathway in human umbilical vein endothelial cells]. Nan fang yi ke da xue xue bao = Journal of Southern Medical University. 2016;36:105561.

[7] Masha A, Brocato L, Dinatale S, Mascia C, Biasi F, Martina V. N-acetylcysteine is able to reduce the oxidation status and the endothelial activation after a high-glucose content meal in patients with Type 2 diabetes mellitus. Journal of endocrinological investigation. 2009;32:352-6.

[8] Recchioni R, Marcheselli F, Moroni F, Pieri C. Apoptosis in human aortic endothelial cells induced by hyperglycemic condition involves mitochondrial depolarization and is prevented by $\mathrm{N}$-acetyl-L-cysteine. Metabolism: clinical and experimental. 2002;51:1384-8.

[9] Yamagishi S, Amano S, Inagaki Y, Okamoto T, Takeuchi M, Inoue H. Pigment epithelium-derived factor inhibits leptin-induced angiogenesis by suppressing vascular endothelial growth factor gene expression through anti-oxidative properties. Microvascular research. 2003;65:186-90.

[10] Volpe CMO, Villar-Delfino PH, Dos Anjos PMF, Nogueira-Machado JA. Cellular death, reactive oxygen species (ROS) and diabetic complications. Cell death \& disease. 2018;9:119.

[11] Zhang Y, Liu T, Chen Y, Dong Z, Zhang J, Sun Y, et al. CD226 reduces endothelial cell glucose uptake under hyperglycemic conditions with inflammation in type 2 diabetes mellitus. Oncotarget. 2016;7:1201023.

[12] Yu M, Lu G, Zhu X, Huang Z, Feng C, Fang R, et al. Downregulation of VEGF and upregulation of TL1A expression induce HUVEC apoptosis in response to high glucose stimuli. Molecular medicine reports. 2016;13:3265-72.

[13] Surico D, Farruggio S, Marotta P, Raina G, Mary D, Surico N, et al. Human Chorionic Gonadotropin Protects Vascular Endothelial Cells from Oxidative Stress by Apoptosis Inhibition, Cell Survival Signalling Activation and Mitochondrial Function Protection. Cellular physiology and biochemistry : international journal of experimental cellular physiology, biochemistry, and pharmacology. 2015;36:2108-20. 
[14] Tartaglia LA, Dembski M, Weng X, Deng N, Culpepper J, Devos R, et al. Identification and expression cloning of a leptin receptor, OB-R. Cell. 1995;83:1263-71.

[15] Avraham Y, Davidi N, Porat M, Chernoguz D, Magen I, Vorobeiv L, et al. Leptin reduces infarct size in association with enhanced expression of CB2, TRPV1, SIRT-1 and leptin receptor. Current neurovascular research. 2010;7:136-43.

[16] La Cava A, Alviggi C, Matarese G. Unraveling the multiple roles of leptin in inflammation and autoimmunity. Journal of molecular medicine (Berlin, Germany). 2004;82:4-11.

[17] Ke Y, Qiu J, Ogus S, Shen WJ, Kraemer FB, Chehab FF. Overexpression of leptin in transgenic mice leads to decreased basal lipolysis, PKA activity, and perilipin levels. Biochemical and biophysical research communications. 2003;312:1165-70.

[18] Ghantous CM, Azrak Z, Hanache S, Abou-Kheir W, Zeidan A. Differential Role of Leptin and Adiponectin in Cardiovascular System. International journal of endocrinology. 2015;2015:534320.

[19] Lopez-Jaramillo P, Gomez-Arbelaez D, Lopez-Lopez J, Lopez-Lopez C, Martinez-Ortega J, GomezRodriguez A, et al. The role of leptin/adiponectin ratio in metabolic syndrome and diabetes. Hormone molecular biology and clinical investigation. 2014;18:37-45.

[20] Ryan MJ, Coleman TT, Sasser JM, Pittman KM, Hankins MW, Stec DE. Vascular smooth musclespecific deletion of the leptin receptor attenuates leptin-induced alterations in vascular relaxation. American journal of physiology Regulatory, integrative and comparative physiology. 2016;310:R960-7.

[21] Katsiki N, Mikhailidis DP, Banach M. Leptin, cardiovascular diseases and type 2 diabetes mellitus. Acta pharmacologica Sinica. 2018;39:1176-88.

[22] Nogueira GB, Punaro GR, Oliveira CS, Maciel FR, Fernandes TO, Lima DY, et al. N-acetylcysteine protects against diabetic nephropathy through control of oxidative and nitrosative stress by recovery of nitric oxide in rats. Nitric oxide : biology and chemistry. 2018;78:22-31.

[23] Park JH, Kang SS, Kim JY, Tchah H. The Antioxidant N-Acetylcysteine Inhibits Inflammatory and Apoptotic Processes in Human Conjunctival Epithelial Cells in a High-Glucose Environment. Investigative ophthalmology \& visual science. 2015;56:5614-21.

[24] Schnackenberg CG. Oxygen radicals in cardiovascular-renal disease. Current opinion in pharmacology. 2002;2:121-5.

[25] Abdelzaher LA, Imaizumi T, Suzuki T, Tomita K, Takashina M, Hattori Y. Astaxanthin alleviates oxidative stress insults-related derangements in human vascular endothelial cells exposed to glucose fluctuations. Life sciences. 2016;150:24-31. 

coronary artery smooth muscle cells. Journal of biomedical science. 2015;22:5.

\section{Figures}
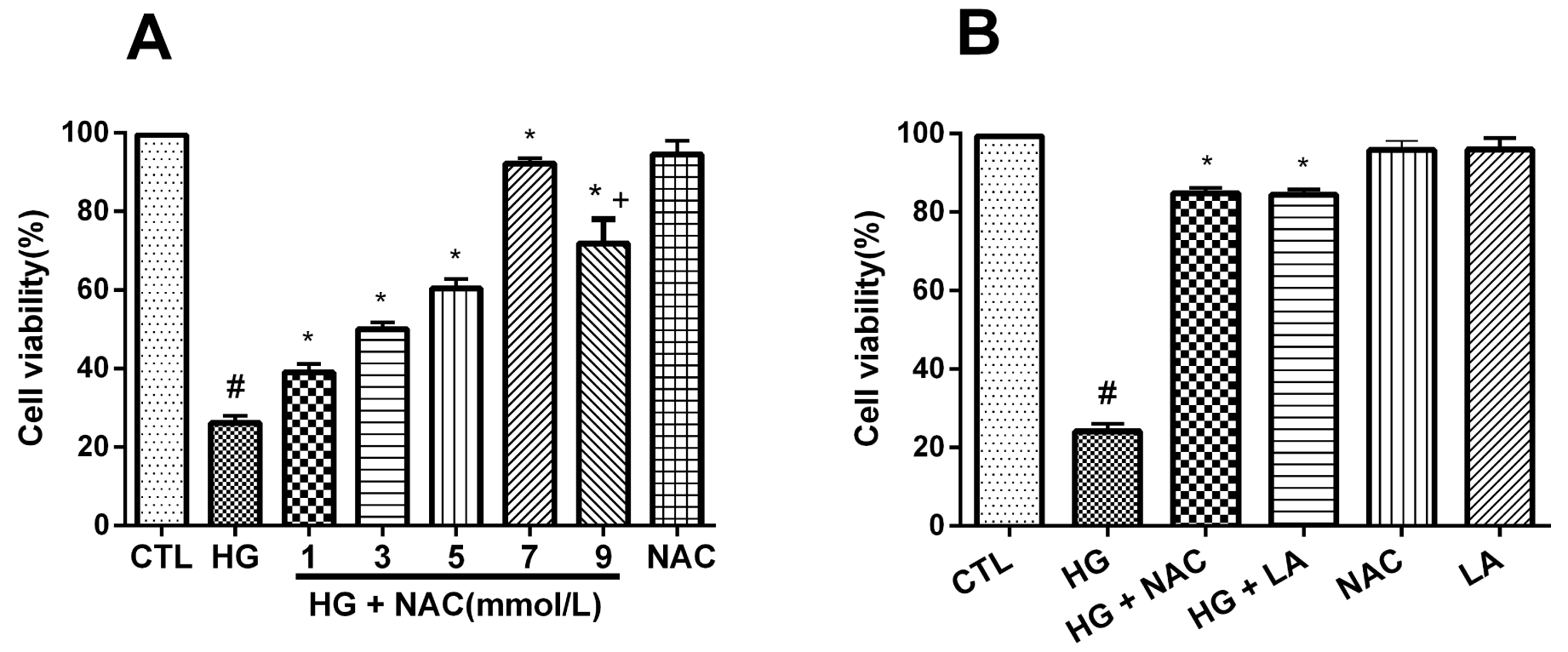

Figure 1

NAC inhibits HG-induced cytotoxicity in HUVECs. Cell viability was detected using the CCK-8 assay. (A) HUVECs were treated with $\mathrm{HG}$ for $24 \mathrm{~h}$ in the absence or presence of pretreatment with the indicated concentrations NAC $(1,3,5,7$ and $9 \mathrm{mmol} / \mathrm{L})$ for 30 min prior to exposure of cells to HG for $24 \mathrm{~h}$. (B) Cells were pretreated with or without $7 \mathrm{mmol} / \mathrm{L}$ NAC or $50 \mathrm{ng} / \mathrm{mL}$ LA for $30 \mathrm{~min}$ prior to exposure of cells to 40 $\mathrm{mmol} / \mathrm{L}$ glucose for $24 \mathrm{~h}$. Data are presented as the mean $\pm S D(n=5)$. $\# P<0.05$ vs $C T L$ group; ${ }^{*}<0.05$ vs HG group; +Pख0.05 vs $7 \mathrm{mmol} / \mathrm{L}$ NAC group. 

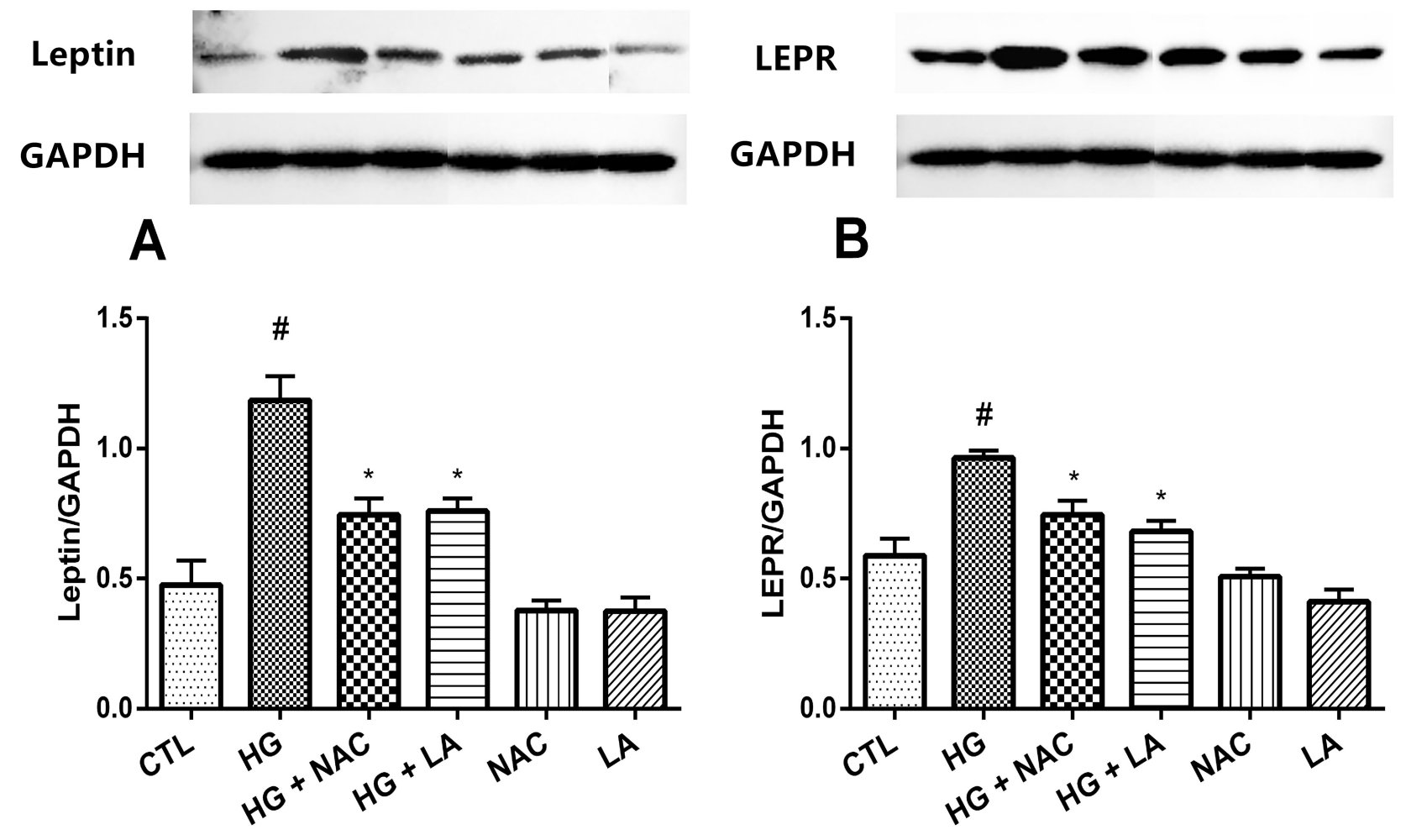

Figure 2

NAC decreases the expression of leptin/LEPR induced by HG in HUVECs. Expression levels of leptin and LEPR were detected using western blot assays. Densitometric analysis of changes in the expression levels of (A) leptin and (B) LEPR in the indicated group. LEPR, leptin receptor. Data are presented as the mean $\pm S D(n=5)$. $\# P<0.05$ vs $C T L$ group; $* P<0.05$ vs $H G$ group. 

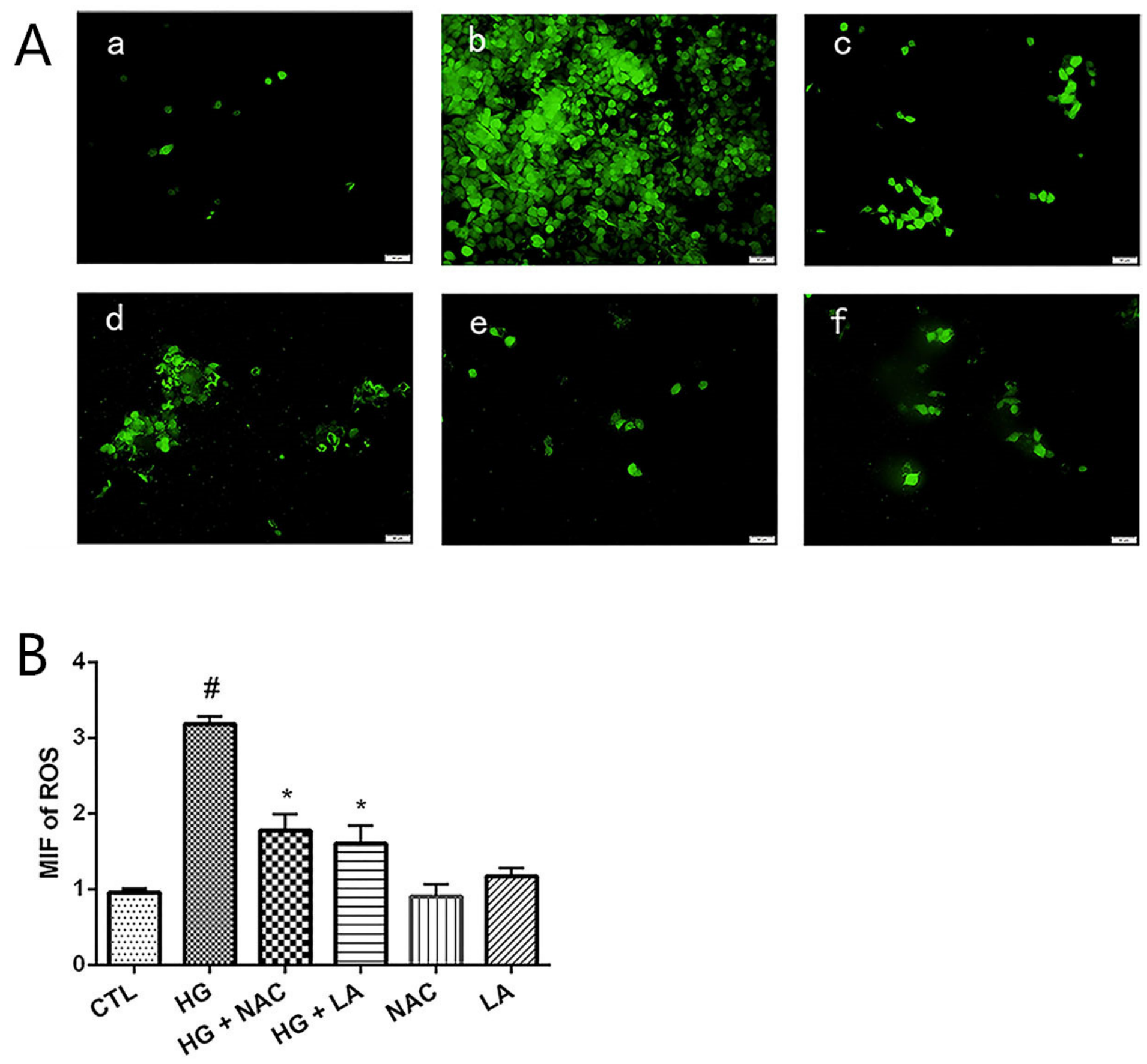

Figure 3

NAC decreases the generation of ROS induced by HG in HUVECs. (A) DCFH-DA staining followed by photofluorography was used to measure intracellular ROS levels. (a) CTL group; (b) HG group; (c) HG + NAC group; (d) HG + LA group; (e) NAC group; (f) LA group. (B) Quantitative analysis of the MFI of DCFHDA using ImageJ 1.47i software. DCFH-DA, 2',7'-dichloro-fluorescein diacetate; MFI, mean fluorescence intensity; ROS, reactive oxygen species; LA, leptin antagonists. Data are presented as the mean \pm SD $(n=5)$. $\# P<0.05$ vs CTL group; ${ }^{*}<0.05$ vs HG group. 


\section{eNOS}

\section{GAPDH}

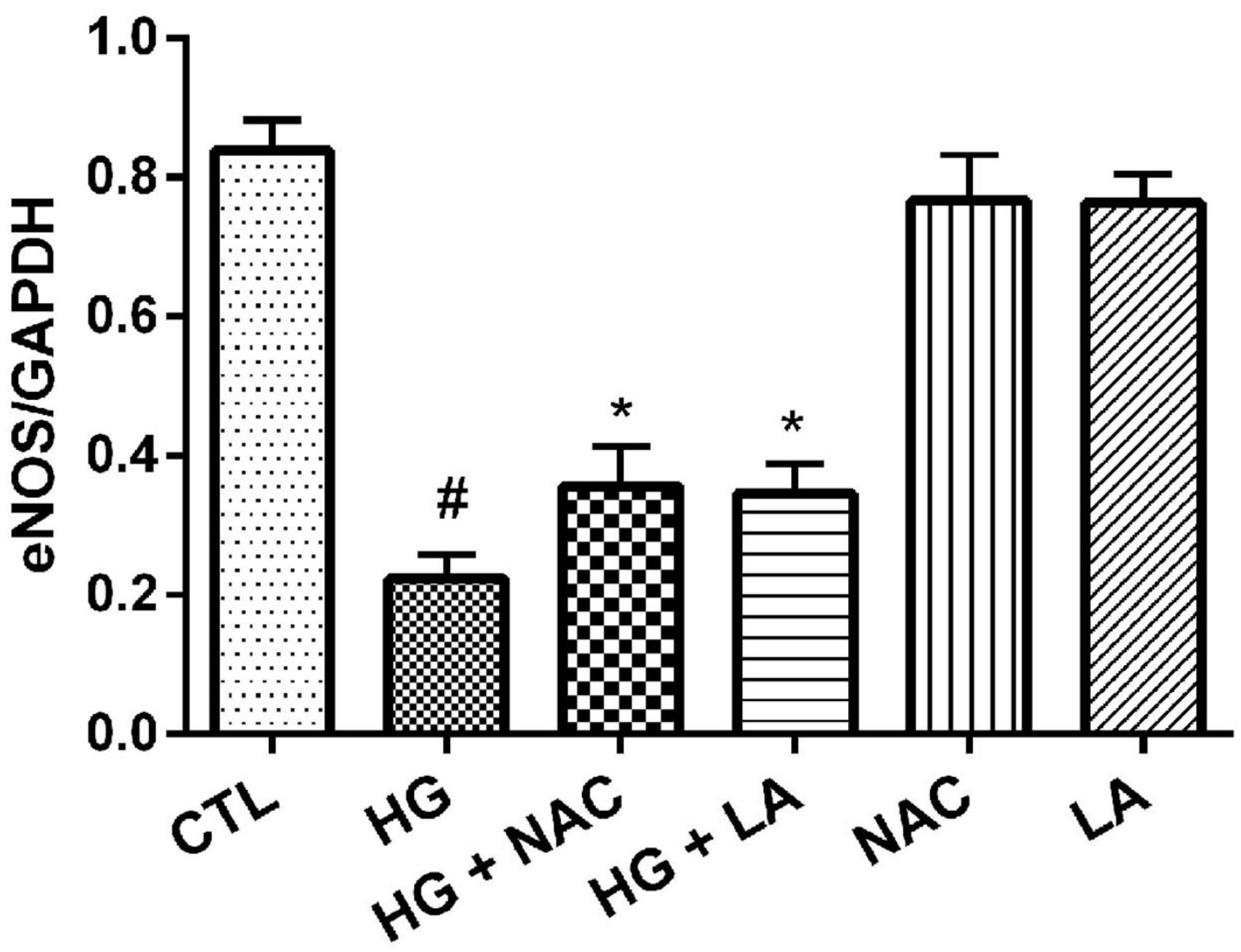

Figure 4

NAC upregulates the decreased expression levels of eNOS induced by HG in HUVECs. The expression levels of eNOS were detected by western blot. eNOS, endothelial nitric oxide synthase. Data are presented as the mean $\pm S D(n=5)$. $\# P<0.05$ vs $C T L$ group; ${ }^{*}<0.05$ vs $H G$ group. 

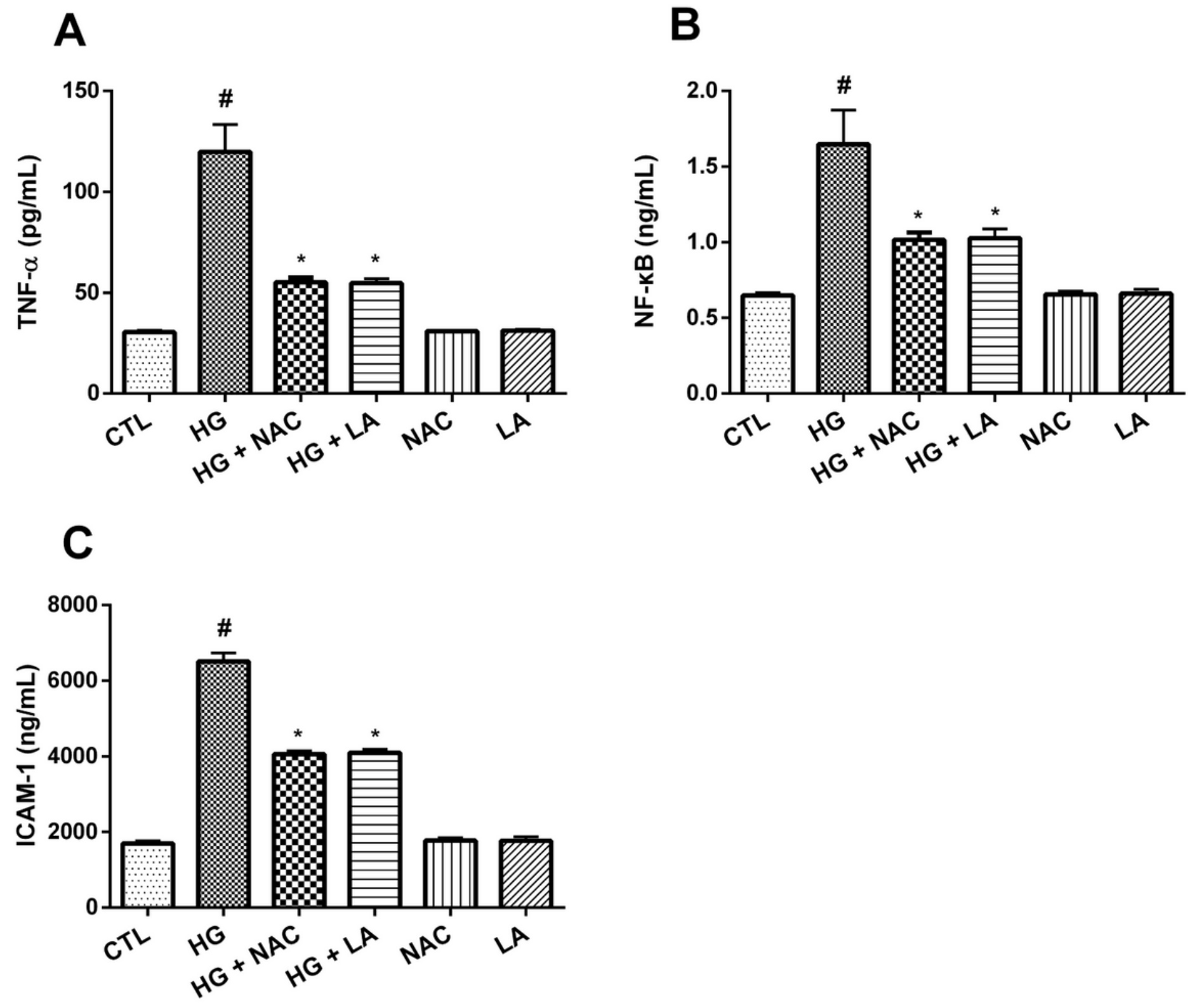

Figure 5

NAC suppress the production of pro-inflammatory cytokines induced by HG in HUVECs. (A) TNF-a区(B) NFKB and (C) ICAM-1 were detected by ELISA. NF-KB: nuclear factor-kappa B; TNF-a: tumor necrosis factor-a; ICAM-1: intercellular adhesion molecule-1. Data are presented as the mean $\pm S D(n=5)$. $\# P<0.05$ vs $C T L$ group; * $\mathrm{P}<0.05$ vs HG group. 

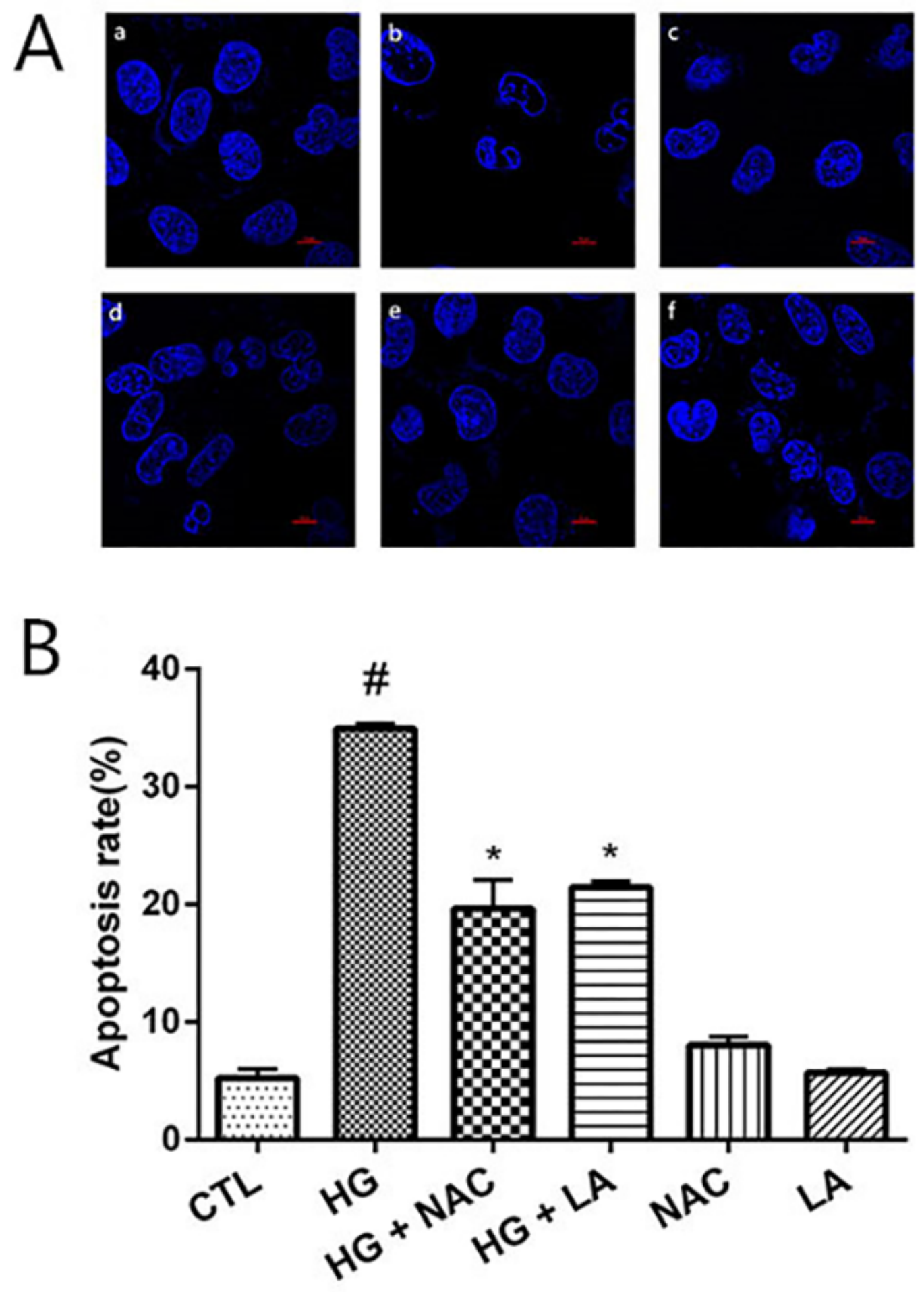

Figure 6

NAC suppress HG-induced apoptosis in HUVECs. (A) Hoechst 33258 nuclear staining followed by fluorescence imaging was performed to examine cell apoptosis. (a) CTL group; (b) HG group; (c) HG + NAC group; (d) HG + LA group; (e) NAC group; (f) LA group. (B) Apoptosis rate was analyzed using ImageJ 1.47i software. Data are presented as the mean $\pm S D(n=5)$. \#P<0.05 vs $C T L$ group; ${ }^{*}<<0.05$ vs HG group. 


\section{Cleaved caspase-3}
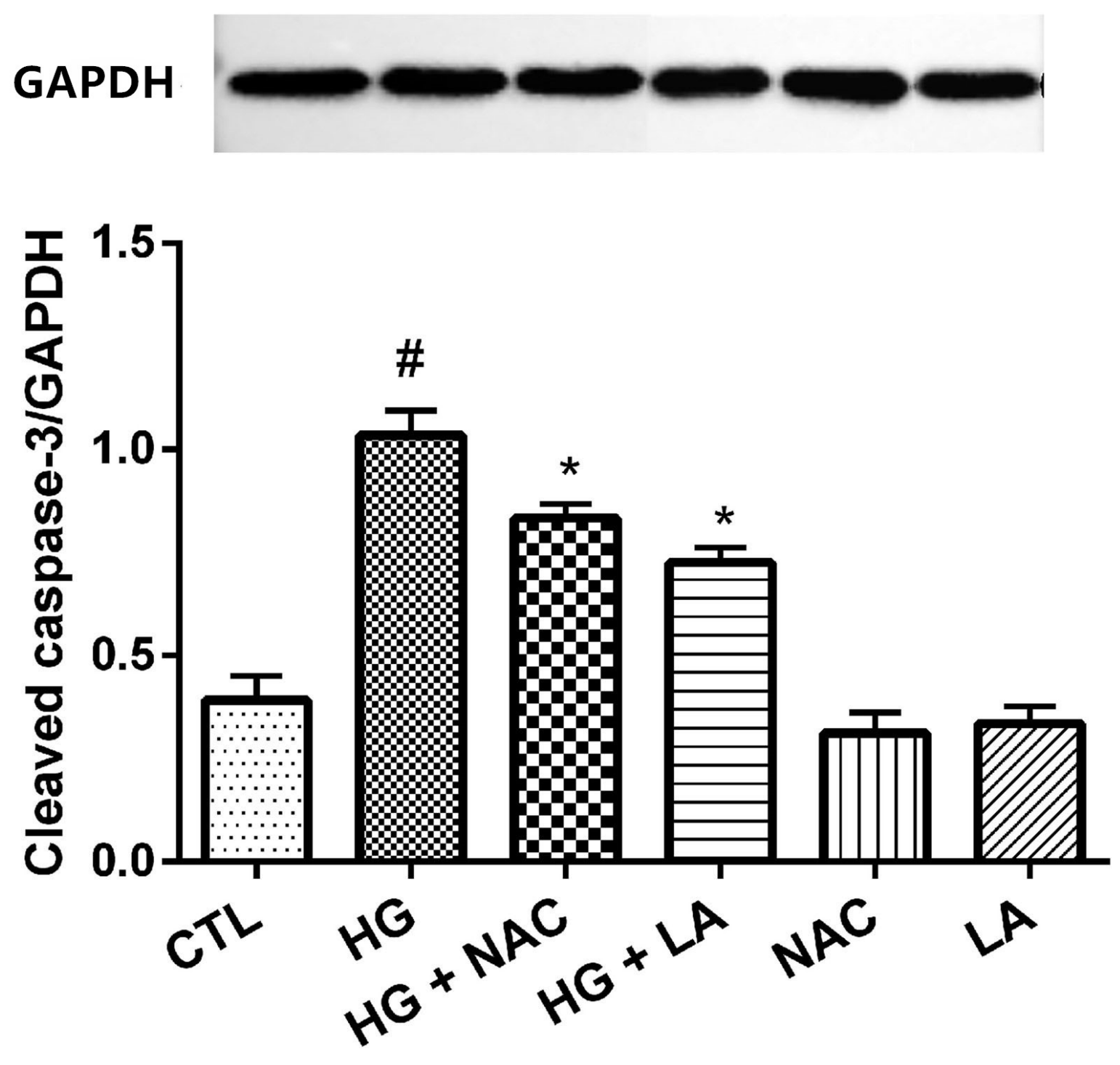

Figure 7

NAC downregulates the increased expression of caspase-3 induced by HG in HUVECs. The expression levels of cleaved caspase- 3 were detected by western blot. Data are presented as the mean $\pm S D(n=5)$. $\# \mathrm{P}<0.05$ vs $\mathrm{CTL}$ group; ${ }^{*}<0.05$ vs $\mathrm{HG}$ group. 

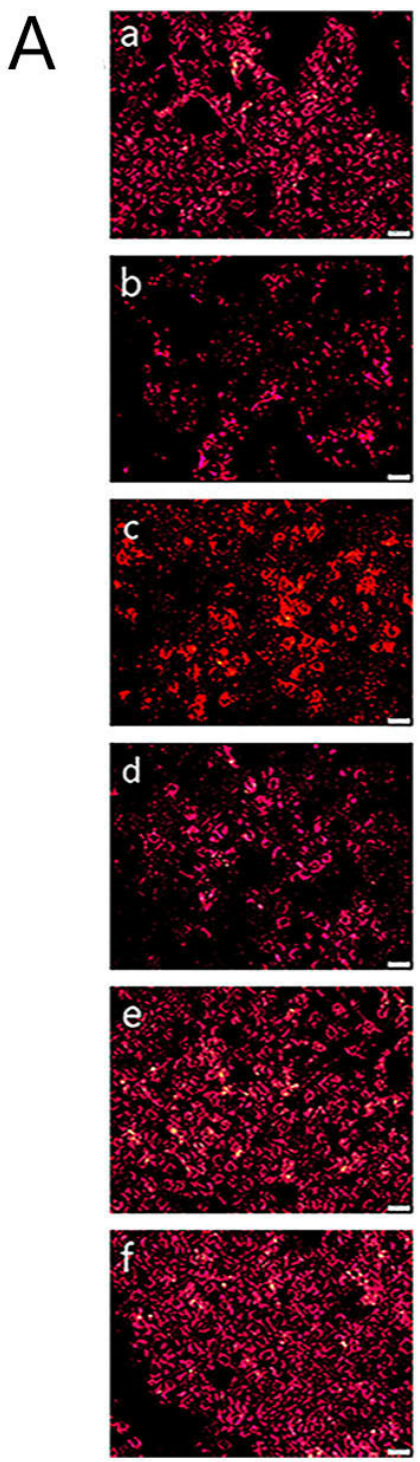
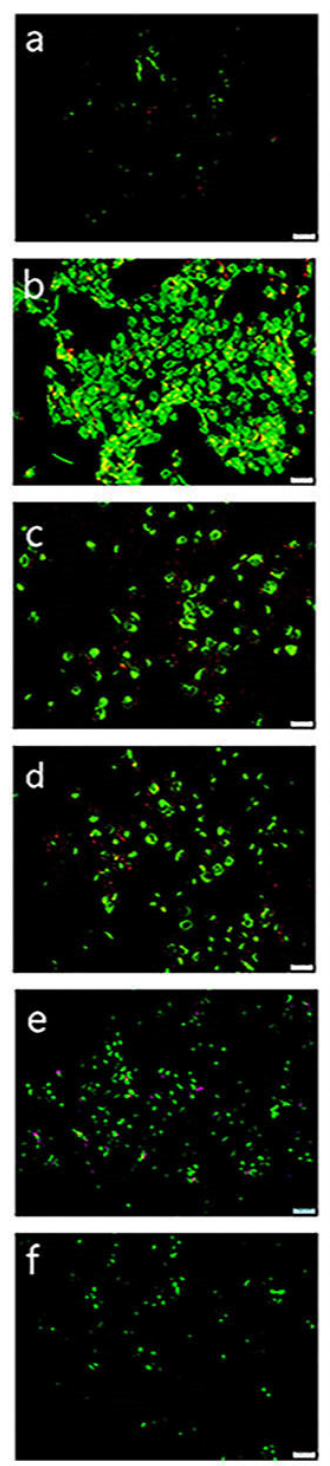
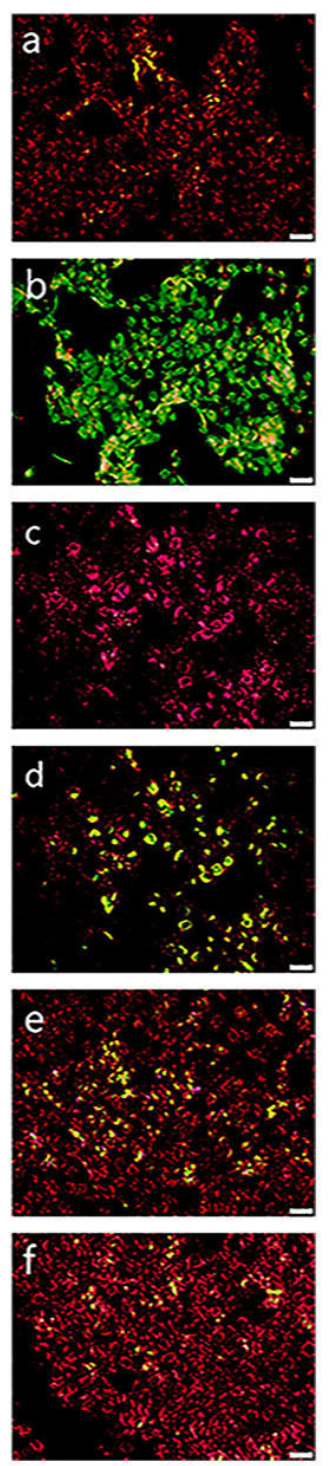

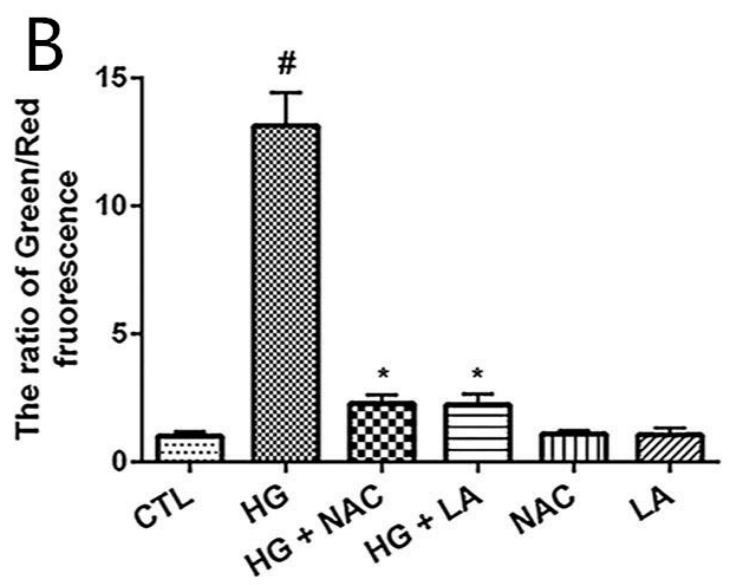

Figure 8

NAC inhibits HG-induced mitochondrial injury in HUVECs. (a) CTL group; (b) HG group; (c) HG + NAC group; (d) HG + LA group; (e) NAC group; (f) LA group. Data are presented as the mean $\pm S D(n=5)$. $\# \mathrm{P}<0.05$ vs $\mathrm{CTL}$ group; ${ }^{*} \mathrm{P}<0.05$ vs $\mathrm{HG}$ group. 